\title{
Para compreender as políticas públicas: uma leitura introdutória
}

Caio Penko ${ }^{1}$

\section{Resumo}

O campo de saber das políticas públicas tem se consagrado como lócus de discussão de notória centralidade para debater grandes questões sociais, econômicas e ambientais que perpassam entre as mais diversas problemáticas, tais como a área da educação, saúde, habitação, entre outras, que exemplificam a importância da abordagem adotada pelo estudo das políticas públicas para se compreender com mais clareza os limites e possibilidades de intervenção do Estado. É neste cenário que a professora da Universidade de São Paulo, Dra. Marta M. Assumpção Rodrigues, se propõe a traçar os caminhos de seu livro intitulado Políticas Públicas, editado pela Publifolha em 2010 - Coleção Folha Explica. Dito isso, a presente resenha tem como objetivo primordial apresentar brevemente as características centrais da publicação em questão, tratando do panorama histórico-institucional e teórico do campo das políticas públicas, contemplando as diversas interfaces que tal empreitada requer.

O campo de saber das políticas públicas tem se consagrado como lócus de discussão de notória centralidade para debater grandes questões sociais, econômicas e ambientais. Estes debates perpassam dentre as mais diversas problemáticas, tais como as áreas de educação, saúde, habitação, desenvolvimento sustentável, reconhecimento social, entre outras, que exemplificam a importância da abordagem adotada pelo estudo das políticas públicas para se compreender com mais clareza os limites e as possibilidades de intervenção do Estado. Vale dizer, também, que este campo é, por excelência, multidisciplinar e qualquer esforço em trabalhar a temática deve em observância a esta relevante característica, agregar ao rol de preocupações

\footnotetext{
${ }^{1}$ Formado em Gestão de Políticas Públicas pela Universidade de São Paulo. Atualmente é Especialista em Políticas Públicas no Governo do Estado de São Paulo. Agradeço a leitura atenta e os comentários de Paula Penko Teixeira (FEA-USP) e Fabio Karam (Unicamp).
} 
dos estudiosos, os diversos pontos de vista e interpretações, assim como múltiplas linhas teóricas que compõe este campo do saber.

É neste cenário que a professora da Universidade de São Paulo, Dra. Marta M. Assumpção Rodrigues, se propõe a traçar os caminhos de seu livro intitulado Políticas Públicas, editado pela Publifolha em 2010 - Coleção Folha Explica. A tarefa a que se coloca a autora foi combinar - de maneira complementar e construtiva - dois desafios que não necessariamente dialogam com facilidade, a saber: i) por um lado, sistematizar uma série de produções teóricas e analíticas clássicas que constituem obras-referência ao estudo do campo das políticas públicas e, ii) por outro lado, salvaguardar a objetividade textual sem, no entanto, abdicar de certos detalhes que representam os principais tópicos e contribuições destes autores. Dito isso, o objetivo primordial desta publicação é apresentar um panorama histórico-institucional e teórico do campo das políticas públicas, contemplando as diversas interfaces que tal empreitada requer.

Para fins meramente didáticos o livro está dividido em três partes que se pretendem constituir um todo inteligível, capaz de articular diversos conceitos e noções teóricas. Além de, concomitantemente, retratar momentos históricos cruciais para o estudo do campo das políticas públicas em uma linha de raciocínio clara e objetiva.

A primeira parte busca apresentar conceitos básicos para então, introduzir efetivamente a discussão centrada nas políticas públicas. Entre os tópicos elencados pela autora, está o Estado retratado como uma instituição que pertence e interage num complexo social de determinado território e que está concatenado de forma indissociável a certas transformações históricas, assim como o Governo pode ser caracterizado por certos indivíduos e grupos sociais que ascendem ao poder, por via institucionalizada ou revolucionária, e que atuam sob a égide do poder político na orientação da sociedade.

Outro aspecto é a definição de atores políticos que influenciam os rumos da sociedade, nas particularidades de seus interesses e capacidade de fazêlos valer, em interação com o Estado. Neste ponto, conclui a autora, que "a eficácia das políticas públicas depende do grau de eficiência da gestão - o que, por sua vez, implica não apenas a qualidade dos gestores para exercer seu oficio público, mas também um ambiente de atuação que favoreça a 
governança democrática e a responsabilização política (accountability)" (RODRIGUES, 2010 p. 24).

A segunda parte concentra-se detidamente sobre os modelos e conceitos das políticas públicas. O leitor observará que o conceito de políticas públicas não é único, consensual. Nesta parte, o capítulo chama atenção para as características do modelo marxista baseado na possibilidade emancipatória que reside na classe trabalhadora, já que sob a "ótima marxista, o diagnóstico é de que instituições políticas e sociais constituem o meio para se alcançar a emancipação econômica da classe operária" (RODRIGUES, 2010 p. 32). Diferentemente do modelo anterior, temos o modelo elitista, que basea-se na perspectiva de que aqueles que detêm a maior parte do poder de influenciar ou até mesmo decidir as políticas públicas, constituem a Elite, conforme aponta os estudos de Horald D. Lasswell (1936) e David Lerner (1951) ao definir o campo das políticas públicas como o desdobramento da tríade: quem ganha o quê, quando e como.

Nesta trajetória, a autora destaca a contribuição do behaviorista Herbert Simon (1978) introduzindo a idéia de racionalidade como categoria analítica dentro do estudo das políticas públicas. Não menos importante, alerta a autora, foi a contribuição de Charles Lindblon (1959) ao constituir a linha de pensamento incremental, isto é, um complexo resultado de decisões historicamente articulados, já que "o modelo incremental parte do pressuposto de que o Governo não tem total liberdade para alocar os recursos públicos, pois essa decisão envolve relações de poder e não se resume, apenas, a uma questão técnica" (RODRIGUES, 2010 p.40).

Representado por Robert Dahl, o modelo pluralista entende que o Estado opera num contexto de multiplicidade de relações de poderes, de interesses diversos no qual a sociedade civil pode influenciar as ações do governo. O que o governo faz ou deixa de fazer é a máxima deste modelo consagrado como "as duas faces do poder" e, nesta visão, as políticas públicas podem ser analisadas tanto pelo que o governo efetivamente faz quanto pelo que deliberadamente deixa de fazer, sendo que ambas são opções políticas. Esta interpretação difere do entendimento exposto por Theodore J. Lowi (1964) ao propor a tipologia das políticas publicas como - essencialmente circunscritas em três arenas: i) distributiva; ii) regulatória; iii) redistributiva. 
Não menos importante, a autora trata das políticas públicas como o processo complexo de gestão, entendido como a formação da agenda pública - destaque ao modelo de correntes múltiplas (multiple streams) de Kingdon (1984) e ao modelo da "lata de lixo" (garbage can) -, que resulta no ciclo de formulação, implementação, monitoramento e avaliação das políticas públicas.

$\mathrm{Na}$ terceira parte a discussão é direcionada a traçar uma relação entre os modelos das políticas públicas no âmbito das questões sociais. Para tanto, se discute diversas dimensões como o momento histórico do capitalismo que foi registrado como Estado de Bem-Estar Social (Welfare State), assim como a construção da cidadania proposta pelos tipos básicos de Thomas Marshall (1967) - direito civil (sec. XVIII), político (séc.XIX) e social (sec. XX) - e, também, os modelos de democracia propostos por Gosta Esping-Andersen (1991) - Social-Democracia, Liberal e Conservador. Especificamente no caso brasileiro, a autora aponta a construção inicial da democracia baseada na práxis de uma cidadania caracterizada por uma origem entendida como a cidadania regulada, nos termos de Wanderley do Santos (1979). Em uma breve retomada da formação econômica e social do Brasil, Marta Rodrigues aponta as mudanças significativas de uma sociedade de base agrária para urbanoindustrial que impactaram de diversas formas na consolidação do Estado e, respectivamente, na sua base institucional-legal imersa na relação com os fenômenos políticos como patrimonialismo, cooptação e corporativismo.

Este é, em linhas gerais, todo o percurso histórico, teórico e analítico proposto por Marta Rodrigues como imperativos básicos para se entender 0 campo das políticas públicas, nos limites e perspectivas que são próprios de uma leitura introdutória.

A escrita requer dedicação como pressuposto para qualidade, ainda mais quando se quer ser interessante e didático diante de temas complexos e polêmicos. Assim, é indubitável que a autora, no texto ora analisado, serve-se da recomendação que foi ensinada pelo realismo crítico do mestre alagoano Graciliano Ramos (1948):

Deve-se escrever da mesma maneira como as lavadeiras lá de Alagoas fazem seu ofício. Elas começam com uma primeira lavada, molham a roupa suja na beira da lagoa ou do riacho, torcem o pano, molham-no novamente, voltam a torcer. Colocam o anil, ensaboam e 
torcem uma, duas vezes. Depois enxáguam, dão mais uma molhada, agora jogando a água com a mão. Batem o pano na laje ou na pedra limpa, e dão mais uma torcida e mais outra, torcem até não pingar do pano uma só gota. Somente depois de feito tudo isso é que elas dependuram a roupa lavada na corda ou no varal, para secar. Pois quem se mete a escrever devia fazer a mesma coisa. A palavra não foi feita para enfeitar, brilhar como ouro falso; a palavra foi feita para dizer.

O que se pretende dizer é que a leitura desta publicação consiste numa abordagem necessária, ainda que inicial, para compreender o estudo do campo das políticas públicas. Esta é a contribuição que Marta M. Assumpção Rodrigues propõe ao leitor de sua obra. Por assim dizer, esta publicação realiza aproximações ao enigma do que são as políticas públicas, sem perder de vista a recomendação de que a "palavra não foi feita para enfeitar, brilhar como ouro falso; a palavra foi feita para dizer". Destinada tanto aos estudantes de gestão de políticas públicas e administração pública quanto para outras formações que tenham alguma interface com a temática, a obra cumpre o papel a que se propõe. Ou seja: uma síntese crítica e atualizada do tema das políticas públicas.

Naturalmente que o interesse da presente resenha restringiu-se tão somente a destacar alguns temas tratados no livro, recomenda-se machadianamente, por tanto, que construa teu próprio julgo, desnecessário dizer que aqui se advoga a favor da leitura da obra. $O$ que não significa 0 abandono do crivo crítico ao leitor interessado na temática, uma vez que "a obra em si mesma é tudo: se te agradar, fino leitor, pago-me a tarefa; se te não agradar, pago-te com um piparote, e adeus" já dizia Brás Cubas.

\section{Bibliografia}

ESPING-ANDERSEN, G. 1991. "As três economias Políticas do Welfare State" In. Lua Nova, n. 24, p.85-116.

HAROLD, D. L. 1936. Politics: Who Gets What, When, How. OH: Cleveland. Meridian Books. 
D. L. \& LERNER, D. (orgs). 1951. The policy Sciences: Recent Developments in Scope and Method. CA: Standford. Standford University Press.

KINGDON, J. W. 1984. Agendas, Alternatives and Public Policies. Boston: Little Brown.

MARSHALL, T. H. 1967. Cidadania, Classe Social e Status. Rio de Janeiro: Ed. Zahar.

LINDBLOM, C. E. 1959. The Science of Muddling Through. In: Public Administration Review, n. 19. P. 78-88.

LOWI, T. 1964. American Business, Public Policy, Case-Studies, and Political Theory. In: World Politics, vol. 16. Princeton: Princeton University.

RAMOS, G. Entrevista concedida em 1948 para uma revista da época. Fonte: www.graciliano.com.br

SANTOS, W. G. 1979. Cidadania e Justiça. Rio de Janeiro: Campus.

SIMON, H. 1957. Comportamento Administrativo. Rio de Janeiro: Ed. Usaid. 